\title{
Clinical laboratory environmental contamination: use of a fluorescence/bacterial tracer
}

\author{
D A KENNEDY, J F STEVENS, * A N HORN From the Supplies Technology Division, NHS \\ Procurement Directorate, Department of Health and Social Security, Russell Square, London, and *Department \\ of Biochemistry, St Stephen's Hospital, London
}

SUMMARY A "Centrifichem" centrifugal analyser was found using a double fluorescence/bacterial tracer method to be a source of airborne and surface contamination in the laboratory. The airborne contamination was controlled by a modification incorporating a filter. Ubiquitous surface contamination generally accompanied the processing of simulated patients' sera.

Double tracer samples could be used in laboratories to assess the quality of hygiene practices in the same way as quality control samples are currently used to assess the quality of analytical performance. The findings indicated a lack of understanding of basic hygiene practices in the laboratory.

A previous unpublished study showed that an "Encore" centrifugal analyser (Baker Instruments, Windsor, Berkshire) produced aerosol when operated in the recommended way. A modification consisting of a centrifugal extractor fan, downstream of which was a high efficiency particulate air [HEPA] filter, was made. The fan was electronically programmed to extract air during the wash cycle, the part of the analytical process that produced aerosol. The developmental work was done at the Public Health Laboratory Service's Centre for Applied Microbiology and Research who showed the effectiveness of this type of filter in the control of airborne contamination (V Lach, personal communication).

A similar modification was constructed by the United Kingdom supplier (Baker Instruments Ltd) which enabled an earlier analyser, the "Centrifichem", to be provided with a HEPA filter extract system. A study of airborne and surface contamination was undertaken on a Centrifichem analyser in routine use in a clinical chemistry laboratory. Airborne contamination was investigated before and after a HEPA filter was fitted to the analyser. As the filter modification changed the flow path of the effluent air it meant that this might have affected the temperature regulation of the Centrifichem, which in turn might have affected the analytical performance, especially of enzyme assays. Accordingly, accuracy and precision of three temperature sensitive assays was evaluated before and after the HEPA filter was fitted. The study also provided an opportunity to investigate surface contamination associated with the use of the

Accepted for publication 23 June 1988
Centrifichem, other analytical equipment, and manual laboratory procedures.

\section{Material and methods}

DOUBLE TRACER SAMPLES ${ }^{1}$

Horse serum was used as the base material. The tracers added were spores of Bacillus subtilis, var. globigii, NCTC 10073, (BG) (Microbial Technology Laboratory, PHLS CAMR, Porton, Wiltshire) and Uvitex NFW (Hughes and Hughes Ltd, Elms Industrial Estate, Romford, Essex) at concentrations of $10^{8} \mathrm{cfu} / \mathrm{ml}$ and $0.1 \%$, respectively. BG spores have been widely used in aerobiological and surface contamination studies and are generally considered to be harmless. ${ }^{2}$ BG colonies produce a characteristic orange pigment that simplifies identification in the presence of normal background fiora. Uvitex NFW is a liquid distyryl biphenyl-derivative optical brightener of very low toxicity. ${ }^{3}$ It is an intensely fluorescent agent which, when excited at $350 \mathrm{~nm}$, emits light at $438 \mathrm{~nm}$. This subvisible emission is visualised and photographed using an ultraviolet light source. The incorporation of $0 \cdot 1 \% \mathrm{v} / \mathrm{v}$ Uvitex NFW into nutrient agar or horse serum failed to inhibit colony formation from BG spores. To investigate surface contamination by manual techniques and that associated with other items of analytical equipment, a pilot study was undertaken in which simulated patients' samples containing double tracers were used.

INVESTIGATION OF AIRBORNE CONTAMINATION The Centrifichem rotor was first charged with double tracer serum by filling a reagent reservoir, then by 
using the pipetting station to dispense the serum into the rotor. Two Bourdillon-type slit samplers, ${ }^{4}$ sampling at a rate of $30 \mathrm{l} /$ minute, were used. One of these, fitted with a $600 \mathrm{~mm}$ extension tube, aspirated air at the front of the analyser level with the rotor chamber lid and about $200 \mathrm{~mm}$ away from it. The other sampled air at the rear of the analyser in the vicinity of the exhaust fans. A 3-stage impinger ${ }^{5}$ also aspirated air at 111 /minute on the bench adjacent to the Centrifichem - that is, level with the lid of the rotor chamber and about $200 \mathrm{~mm}$ away from it. The samplers were run for seven minutes. Settle plates were mounted on the top of the pipetting station in the vicinity of the sample and reagent probes. An analysis programme was selected that included a four and a half minute run and a two minute wash cycle.

INVESTIGATION OF SURFACE CONTAMINATION

Aliquots of the double tracer serum were carefully pipetted into each of six glass screw-capped tubes used by the laboratory for postal specimens. After ensuring that the caps were tight and that there was no contamination on the outside the tubes were placed in a tray in the laboratory reception area, each with a request form made out for electrolytes, a bone profile, cardiac enzymes, and a "stat" urea, sodium and potassium. The object was to have the test sera analysed by a wide range of laboratory instrumentation. A chromatography lamp was used to examine the areas where the double tracer sera had been handled. Where fluorescence was detected, the area was swabbed. An area of a bench that did not show fluorescence was swabbed as a negative control. The swabs and a control sample of the test serum were then plated out.

Nutrient agar was used throughout. Plates were incubated aerobically at $37^{\circ} \mathrm{C}$ for 16 hours, then kept for 10 hours at ambient temperature to develop the BG pigment before examination.

A series of quality control sera with values for creatine kinase, aspartate transferase, and alkaline phosphatase were assayed each day for one week before the HEPA filter was fitted and this was repeated for one week after the modification.

\section{Results}

The double tracer serum gave a good yield of BG colonies, an area of work bench that showed no fluorescence yielded no BG; and a sample of the laboratory air taken with a slit sampler before experiments were done yielded no BG colonies. The results of the study of airborne contamination associated with the Centrifichem before the HEPA filter exhaust modification are given in table 1 .

Aerosol was produced during the filling of the rotor and during assay runs when the rotor was spinning; in
Table 1 Airborne contamination in a clinical chemistry laboratory associated with Centrifichem analyser without HEPA-filtered exhaust

\begin{tabular}{|c|c|c|}
\hline Activity & Slit sampler & $\begin{array}{l}\text { Three-stage } \\
\text { impinger }\end{array}$ \\
\hline Filling rotor & $\begin{array}{l}\text { Front = } 1 \text { BG colony; } \\
\text { rear = no BG colonies }\end{array}$ & $\begin{array}{l}\text { BG colonies } \\
\text { recovered at } \\
\text { stages } 2 \text { and } 3^{*}\end{array}$ \\
\hline $\begin{array}{l}\text { Assay run 1; } \\
\text { rotor spinning }\end{array}$ & $\begin{array}{l}\text { Front = } 1 \text { BG colony; } \\
\text { rear = 26 BG colonies }\end{array}$ & $\begin{array}{l}\text { BG colonies } \\
\text { recovered at } \\
\text { stages } 2 \text { and } 3^{*}\end{array}$ \\
\hline $\begin{array}{l}\text { After assay run 1; } \\
\text { rotor not spinning } \\
\text { Assay run 2; } \\
\text { rotor spinning }\end{array}$ & $\begin{array}{l}\text { Front = } 1 \text { BG colony; } \\
\text { rear = no BG colonies } \\
\text { Front = no BG colonies; } \\
\text { rear = } 28 \text { BG colonies }\end{array}$ & $\begin{array}{l}\text { BG colonies } \\
\text { recovered at } \\
\text { stages } 2 \text { and } 3^{*}\end{array}$ \\
\hline $\begin{array}{l}\text { After assay run } 2 \\
\text { rotor not spinning }\end{array}$ & $\begin{array}{l}\text { Front = } 1 \text { BG colony; } \\
\text { rear = } 3 \text { BG colonies }\end{array}$ & \\
\hline
\end{tabular}

the latter case BG colonies were grouped together indicating that aerosol production is the result of a single event, probably the wash cycle. After the HEPA filter modification the test sequence was repeated using only slit samplers. No BG was recovered, indicating the efficiency of the filter. Surface contamination due to splashing of double tracer serum, evidenced by fluorescence, was detected after operating the Centrichem system. This was seen on surfaces close to the sampling probe of the pipetting station; on the sample cup platen; on the analysis rotor in the vicinity of the drainage holes. Finger contamination, caused by removing the snap-on closures of sample cups, was also detected and on surfaces touched by tracercontaminated fingers, such as unused sample cups. Splashes of tracer could also be seen above the surface

Table 2 Environmental surface contamination in a clinical chemistry laboratory

\begin{tabular}{|c|c|c|}
\hline Location & Fluorescence & BG colonies \\
\hline \multicolumn{3}{|l|}{ Serum separating area: } \\
\hline Outside of specimen tubes & $+t+$ & $++t$ \\
\hline Discarded disposable gloves & $+t+$ & $++t$ \\
\hline & $++t$ & +++ \\
\hline [under bench] & +++ & +++ \\
\hline Non-fluorescent area of bench & - & - \\
\hline \multicolumn{3}{|l|}{ Urgent sample area: } \\
\hline Bench & ++ & ++ \\
\hline Sample port of urea analyser & ++ & $++t$ \\
\hline \multirow{2}{*}{\multicolumn{3}{|c|}{ Automated equipment area: }} \\
\hline & & \\
\hline Centrifugal analyser rotor & ++ & $++t$ \\
\hline Transfer rack & +++ & $++t$ \\
\hline Transfer disc & $+t+$ & +++ \\
\hline \multicolumn{3}{|l|}{ Inside of discard bucket containing } \\
\hline sodium hypochlorite solution & $++t$ & - \\
\hline Computer keyboard & + & $\begin{array}{l}\text { Not } \\
\text { cultured }\end{array}$ \\
\hline Multichannel analyser sample rotor & +++ & $++t$ \\
\hline
\end{tabular}


of disinfectant on the side of the waste pot used for disposal of used sample cups and pipettes.

The results obtained using the simulated patients' samples are given in table 2; contamination was widespread. Failure to isolate BG from the discard bucket is attributed to the effect of chlorine derived from the hypochlorite disinfectant contained inside it.

Only a few BG colonies were isolated from the ionselective electrode and this was attributed to an attempt at disinfection with sodium hypochlorite solution. In two places - the reception bench and multichannel analyser sample tray-the smeared pattern of fluorescence suggested that an attempt had been made to wipe up a spillage. The isolation of BG from these areas showed that this had not been effective. There was no detectable difference in the analytical performance of the Centrifichem before or after the HEPA filter modification was fitted.

\section{Discussion}

Spinning cups generate homogeneous aerosols with liquid droplets above $15 \mu \mathrm{m}$ in diameter. ${ }^{6}$ The Centrifichem gave rise to a respirable aerosol-that is, in the order of $5 \mu \mathrm{m}$ in diameter-and this is probably due to the drying down of the initial droplets when entrained in the air currents produced by the rotor. The analyser has a side fan (flow 9 metres/second) and rear fans (flow 1-4 metres/second). Thus aerosol produced by the spinning rotor and containing solids derived from patients sera, including any microbes present, can be broadcast wide of the analyser.

The HEPA filter assembly proved effective in controlling the dissemination of airborne contamination, did not seem to affect analytical performance, and can be recommended as a modification for other Centrifichems. Studies of environmental surface contamination were done by Lauer ${ }^{7}$ and Piazza, ${ }^{8}$ who studied blood contamination with hepatitis virus in clinical laboratories and dental surgeries, respectively, by detection of $\mathrm{HBsAg}$ and by a radioimmunoassay. Holton studied the contamination in clinical laboratories and venepuncture clinics using a microbial tracer and a forensic science test for blood"; and Beaumont studied blood contamination of a necropsy suite by means of "Hemastix" reagent strips. ${ }^{10}$ These studies and ours showed ubiquity of surface contamination by blood or serum. It should be borne in mind that in our study only six test samples were used but normally about 200 patients' samples are handled daily in the laboratory; therefore the real level of serum contamination is likely to be much greater than our limited study suggests.

Infection with hepatitis B virus (HBV) remains a definite but low level problem in British clinical laboratories, and, together with other infections, indicates that there is scope for improvement in standards of technical performance. "Blood from an infected patient is the most common and effective vehicle of transmission of $\mathrm{HBV}$ and the main risk arises from percutaneous contamination. ${ }^{12}$ Very high infectivity titres of $\mathrm{HBV}$ in blood $-10^{8}$ to $10^{10}$ infectious virions per $\mathrm{ml}$-have been measured and minute quantities of contaminated blood can therefore transmit $\mathrm{HBV}$ infection. ${ }^{13}$ It is recognised that good basic hygiene practices are among the primary countermeasures against $\mathrm{HBV}$ and laboratory-acquired human immunodeficiency virus infection. ${ }^{14}$

Our findings, like those of Beaumont, ${ }^{10}$ identified a lack of understanding of basic hygiene practices. The double tracer method was simple and convenient to use and provided a combined screening and confirmatory test for the presence of surface contamination. The use of photographs of the fluorescent areas, together with the evidence of positive cultures, have made it easy to indicate to laboratory staff where problems exist so that remedial practices can be adopted.

An important aspect of this study is that it showed how gloves can protect against skin contamination. It should be noted, however, that gloves can easily transmit contamination to surfaces, such as computer keyboards, telephones, and door handles ${ }^{10}$ and can thereby present a risk to unsuspecting workers not wearing gloves.

Finally, we envisage double tracer-containing samples being introduced regularly into the laboratory to enable the assessment of the quality of hygiene practices in the same way as quality control samples are currently used to assess quality of analytical performance.

We thank Ciba Geigy (Dyestuffs and Chemicals) Ltd for a gift of Uvitex NFW and Dr M A Buttolph for his advice in the preparation of this paper.

\section{References}

1 Kennedy DA, Stevens JF. Tracing of laboratory contamination: quality control approach, Lancet 1988;i:471-2.

2 Darlow HM, Simmons DJC, Roe FJC. Hazards from experimental skin painting of carcinogens. Archives of Environmental Health 1969;18:883-93.

3 Ciba-Geigy, Uvitex NFW. Technical circular 6150E. Manchester: Ciba-Geigy Dyestuffs and Chemicals, 1977.

4 Bourdillon RB, Lidwell OM, Thomas JC. A slit sampler for collecting and counting air-borne bacteria J Hyg 1941; 41:197-224.

5 May KR. Multistage liquid impinger. Bacteriological Reviews 1966;30:559-70.

6 Davies CN, Cheah PKP. Spinning generators of homogeneous aerosols. J Aerosol Sci 1984;15:719-39. 
7 Lauer JL, Van Drunen NA, Washburn JW, Balfour HH. Transmission of hepatitis B virus in clinical laboratory areas. J Infect Dis 1979;140:513-16.

8 Piazza M, Guadagnino V, Piccotto L, Borgia G, Nappa S. Contamination by hepatitis $B$ surface antigen in dental surgeries. Br Med J 1987;295:473-4.

9 Holton J, Prince M. Blood contamination during venepuncture and laboratory manipulation of specimen tubes, Journal of Hospital Infection 1986;8:178-83.

10 Beaumont LR. The detection of blood on non-porous environmental surfaces: an approach for assessing factors contributing to the risk of occupational exposure to blood in the autopsy suite. Infection Control 1987;8:424-6.

11 Grist NR, Emslie JAN. Infections in British clinical laboratories, 1984-5. J Clin Pathol 1987;40:826-9.
12 Health Service Advisory Committee [HSAC]. Safety in health service laboratories: Hepatitis $B$. London: Health and Safety Commission, 1985.

13 Purcell RH. The hepatitis viruses: an overview and historical perspective. In: Szmuness W, ed. Viral hepatitis. Philadelphia: Harvey J Alter and James E Maynard, Franklin Institute Press, 1981:3-12.

14 Advisory Committee on Dangerous Pathogens. LAV/HTLVIIIthe causative agent of AIDS and related conditions-Revised guidelines. London: Health and Safety Executive, 1986.

Requests for reprints to: Dr J F Stevens, Division of Pathology, St Stephen's Hospital, Chelsea, London SW10 9TH, England. 